$\xi_{p}$

\title{
Adsorption Studies of Methylene Blue by Encapsulated Nano-Carbonaceous Alginate Beads
}

\author{
W.N. Wan Ibrahim ${ }^{1}$, N.H. Zainal Abidin ${ }^{1}$, N.S. Mohamad Hanapi ${ }^{1}$, N.F. Ab Malek ${ }^{1}$ \\ W.N.A. Wan Sudin ${ }^{1}$, N. Saim ${ }^{1}$, R. Rusmin² \\ ${ }^{1}$ Faculty of Applied Sciences, Universiti Teknologi MARA, 40450 Shah Alam, Selangor, Malaysia \\ ${ }^{2}$ Faculty of Applied Sciences, Universiti Teknologi MARA, Negeri Sembilan Branch, Kuala Pilah campus, 72000 Kuala Pilah, Negeri \\ Sembilan, Malaysia \\ *Corresponding author E-mail: wannazihah@salam.uitm.edu.my
}

\begin{abstract}
Two different nano-carbonaceous materials namely, multi-walled carbon nanotubes and graphene oxide were encapsulated with biopolymer alginate and employed as adsorbents for the removal of methylene blue dye from aqueous solution. To evaluate the performance of synthesized adsorbents, several parameters including adsorbent dosage, sample volume, stirring speed, sample $\mathrm{pH}$, contact time and initial dye concentration were optimized. The optimum conditions were found as follow: $0.1 \mathrm{~g}$ adsorbent dosage, $400 \mathrm{rpm}$ stirring speed, $10 \mathrm{~mL}$ of sample volume, 180 minutes contact time, $\mathrm{pH} 11$ and $20 \mathrm{mg} / \mathrm{L}$ initial concentration of methylene blue. From the results, the encapsulated Alginate-carbonaceous beads gave higher removal percentage as compared to pristine alginate beads. This could attribute by additional hydrophobic and $\pi-\pi$ interaction contributed from aromatic rings of carbonaceous material towards methylene blue molecular structure. Whilst, kinetic studies showed that the adsorption process accurately represented by a pseudo second-order model.
\end{abstract}

Keywords: adsorption; alginate; graphene oxide; multiwall carbon nanotubes.

\section{Introduction}

Dyes have been extensively used in various industries such as textile, leather, paper, cosmetics, plastic, pharmaceutical rubber and food [1]. The extensively used of dyes in various industries and improper disposal has lead series of pollution problems significantly towards aquatic system. Molecular of dye which mainly aromatic structure are biological non-biodegradable, stable to light oxidation, prevent sunlight and oxygen, thus disturb the photosynthesis process in aquatic systems [2]. They also can be degraded to carcinogenic, toxic, and mutagenic compound that will effect on living organisms [3]. Therefore, technologies are needed for the removal of dyes from aqueous solution.

Numerous technologies including ultrafiltration, ion exchange, photocatalysis, adsorption, electro-dialysis, chemical oxidation, chemical precipitation and coagulation have been implemented for the treatment of dyes contaminant [4]. Among these, adsorption technology is the most preferable technique due to easy access, simple operation without entail sludge formation, effectively remove both organic and inorganic pollutants and regeneration of adsorbent [5]. However, improving adsorption efficiency is a great challenges and various adsorbents have potential to lower dyes concentration in aqueous solution such as fly ash [6], saw dust [7], activated carbon, zeolite [8] calcined animal bones [9], mesoporous silica [10], magnetic nanomaterials [11] and graphene oxide [12].

In recent years, carbonaceous materials have been extensively used for adsorption applications such as activated carbon due to their good chemical stability, structural diversity, low density and suitability for large scale production [13]. Carbon nanotubes (CNTs) serve as excellent adsorbents because of their hollow, layered structure and large surface area [14]. The CNTs adsorbents can be grouped into three sorts that are single-walled CNTs (SWCNTs), multi-walled CNTs (MWCNTs) and functionalized CNTs [15]. MWCNTs exhibit excellent adsorption for heavy metal ions, radioactive elements, dye, pesticide and other organic pollutants in the water since its possess small radial size, excellent mechanical properties, outstanding electrical conductivity and thermal conductivity [16]. Another fascinating nanomaterial is graphene oxide (GO), have great attracted attention in wastewater treatment [17]. Owing to massive quantities of oxygen-containing functional groups in carboxyl, epoxy, and have large specific surface area, it could be an excellent choice for the adsorption of various organic molecules such as organic dye, heavy metals and aromatic compounds [18-19].

However, nanoscale MWCNTs and graphene oxide are too small and light to isolate from effluent and these materials are insoluble and easily to clump due to strong inter-tube Van der Waals forces which might tend to give difficulty in adsorption [20]. Therefore, to facilitate phase separation of MWCNTs and GO by functionalize and coupling with superior performance materials. Recently, development encapsulation of carbon materials and biopolymers have been made and represent an interesting option for the removal pollutants due to it can increase hydrophobic sites, surface area and the porosity of the materials. This approach can retain the structure and original properties after modification [21-22].

Alginates are well known in development of adsorbents as well as encapsulation in cell immobilization and drugs delivery due to its nontoxicity, biodegradability and chemical versatility [23]. Alginate is a biopolymer extracted from brown algae and consists of edible polysaccharides with homopolymeric blocks of 1-4 linked $d$-mannuronate and $L$-guluronate [24]. Alginate has been explored as supporting material by encapsulating with activated carbon 
[25], carbon [17], synthetic polymer [26] and maghemite nanoparticles [27] to form as adsorbents for heavy metals, dyes and other pollutants $[1,28]$.

To the best of our knowledge, there are only few investigations focused on comparison adsorption studies towards dyes removal by carbonaceous materials with alginate. Within this framework, the present study focuses on the synthesis and adsorption properties of the encapsulated MWCNTs and GO within alginate in the form of beads. The adsorption performance and kinetic studies have been evaluated to observe the effects of various parameters such as medium acidity, contact time and initial concentration of methylene blue (MB) removal

\section{Experimental section}

\subsection{Materials}

Graphene oxide was purchased from GO Advanced Solution Sdn Bhd and multiwalled carbon nanotubes (MWCNTs) was obtained from Sun Nanotech (Jiangxi, China). Other chemicals such as methylene blue $\left(\mathrm{C}_{16} \mathrm{H}_{18} \mathrm{~N}_{3} \mathrm{SCl} .3 \mathrm{H}_{2} \mathrm{O}\right)$, acetic acid $\left(\mathrm{CH}_{3} \mathrm{COOH}\right)$, sodium hydroxide $\left(\mathrm{NaOH}\right.$, sodium alginate $\left(\mathrm{C}_{6} \mathrm{H}_{7} \mathrm{NaO}_{6}\right)$, calcium chloride and methanol used were purchased from Sigma Aldrich.

\subsection{Instrumentation}

Chemical characteristics of the prepared materials were examined using Fourier Transform Infrared (FTIR) spectroscopy model Perkin Elmer. The morphology of materials was viewed by scanning electron microscopy (SEM) of a TM3030 PLUS instrument. While, Ultra Violet Visible (UV-Vis) Spectrometer (Perkin Elmer Lamda 35, Deuterium Lamp, 190-110 nm) was used to evaluate the adsorption activities of prepared materials toward methylene blue.

\subsection{Procedure}

\subsubsection{Preparation of solutions}

A $1000 \mathrm{mg} / \mathrm{L}$ of $\mathrm{MB}$ dye solution was prepared as stock solution and $100 \mathrm{mg} / \mathrm{L}$ of $\mathrm{MB}$ dye was prepared for working solution. Series of initial MB dye concentration 5, 10, 15, 20 and $25 \mathrm{mg} / \mathrm{L}$ was prepared from $100 \mathrm{mg} / \mathrm{L}$ solution. Then, the standard solution was observed via UV-Vis spectrometer at $\lambda \max 659 \mathrm{~nm}$ to obtain the calibration curve.

\subsubsection{Preparation of alginate beads}

An aqueous solution of 3\% w/v alginate (Alg) was prepared by dissolving the subsequent amount of sodium alginate in deionized water and was vigorously stirred ate constant temperature $60{ }^{\circ} \mathrm{C}$ for $1 \mathrm{~h}$. The solution was then dripped into $0.1 \mathrm{M}$ of calcium chloride $\left(\mathrm{CaCl}_{2}\right)$ solution by using micropipette to form the Alg beads The Alg beads was filtered, washed thoroughly with deionized water and dried at $60{ }^{\circ} \mathrm{C}$ for overnight.

\subsubsection{Preparation of alginate-multiwalled carbon nanotubes and alginate-graphene oxide beads}

Preparation of Alginate-Multiwalled Carbon Nanotubes (AlgMWCNT) and Alginate-Graphene Oxide (Alg-GO) were adapted from previous study [23] with minor modification. $3 \mathrm{~g}$ of sodium alginate powder was dissolved in $60{ }^{\circ} \mathrm{C}$ of $70 \mathrm{~mL}$ deionized water and stirred using magnetic stirrer. A mixture of $0.3 \mathrm{~g}$ of carbonaceous material (MWCNTs or GO) was dispersed using sonication with $30 \mathrm{~mL}$ deionized water for 30 minutes. Then, this solution was mixed with alginate solution and sonicate for further 30 minutes. The mixture was then dripped into $0.1 \mathrm{M}$ of $\mathrm{CaCl} 2$ solution using micropipette and the carbonaceous encapsulated in alginate beads were form upon contact. The beads were filtered, washed with deionized water and dried at $60{ }^{\circ} \mathrm{C}$ for overnight.

\subsubsection{Batch Adsorption Experiment}

Adsorption experiments were carried out at room temperature using batch process on a shaker (400 rpm). Effect of Medium Acidity. A series of MB solution (10 mL, $20 \mathrm{mg} / \mathrm{L}$ ) were adjusted to $\mathrm{pH} 3,5,7,10,11$ and 12 by adding either $\mathrm{HCl}$ or $\mathrm{NaOH}$ solution. Into every MB solution, $0.1 \mathrm{~g}$ adsorbent beads were added, the mixture was shaken for $60 \mathrm{~min}$, and followed by the phase separation using gravity filtration. The residual MB solution was determined with UV-Vis. Adsorption Kinetics. Into a series MB solution $(10 \mathrm{~mL}, 20 \mathrm{mg} / \mathrm{L})$ at optimum $\mathrm{pH} 10,0.10 \mathrm{~g}$ of adsorbent beads was added, shaken for various contact times the range $30-$ $300 \mathrm{~min}$ and followed by the phase separation using gravity filtration. The residual MB in every solution was determined with UVVis. Adsorption Isotherm. Adsorption isotherm was conducted by using a series of $10 \mathrm{~mL}$ MB solution with various concentration at optimum $\mathrm{pH}$. Into every MB solution, $0.10 \mathrm{~g}$ of adsorbent beads was added, shaken for optimum contact time, and followed by the phase separation. The MB concentration in the solution was determined with UV-Vis.

\section{Results and discussion}

\subsection{Characterization of adsorbents}

The Alg beads formed in yellowish color while, Alg-MWCNT and Alg-GO beads adsorbents obtained in black color. The prepared beads have spherical in shape with bead diameter size $<0.2 \mathrm{~cm}$

FTIR analyses were carried out to ascertain the functional groups present in prepared adsorbents. Major absorption bands of Alg, Alg-MWCNT and Alg-GO beads were summarized in Table 1. A slight variation was observed in -OH stretching bands (3348-3263 $\mathrm{cm}^{-1}$ ) and C-H stretching for aromatic rings (2140-2109 $\left.\mathrm{cm}^{-1}\right)$ indicating intermolecular hydrogen bonds occurred between aromatic proton of carbonaceous with the backbone of alginate [29]. While shifting of vibration bands in the range $1423-1417 \mathrm{~cm}^{-1}$ (COO- stretching), 1080-1030 $\mathrm{cm}^{-1}$ (C-O stretching) and 942-940 $\mathrm{cm}^{-1}$ (C-O-C stretching) proved a good miscibility of Algcarbonaceous matrix through $\pi-\pi$ stacking and electrostatic interactions [22, 30-31]

Table 1: Comparison FTIR absorption bands of Alg, Alg-MWCNT and Alg-GO beads

\begin{tabular}{cccc}
\hline \multirow{2}{*}{ Adsorption stretching bands } & \multicolumn{3}{c}{ Wavelength $\left(\mathbf{c m}^{-\mathbf{1}}\right)$} \\
\cline { 2 - 4 } & Alg & Alg-MWCNT & Alg-GO \\
\hline O-H & 3348 & 3345 & 3263 \\
C-H & 2140 & 2109 & 2118 \\
COO & 1423 & 1420 & 1417 \\
C-O & 1080 & 1070 & 1030 \\
C-O-C & 942 & 940 & 941 \\
\hline
\end{tabular}

The morphologies of prepared adsorbent were studied by SEM as shown in Fig. 1. Pristine Alg beads possess smooth outer surface with minimal small pores observed at high magnification, which similar as reported in previous study [32]. While, Fig 2(b-c) show multilayer of MWCNTs and black graphite thick planar sheets of $\mathrm{GO}$ were observed over the exterior surface of alginate indicating high compatibility of carbonaceous within alginate matrix [33-34]. Interestingly, the present of carbonaceous material onto Alg matrix will increased the surface area as well as the adsorption sites of the adsorbents [35]. 

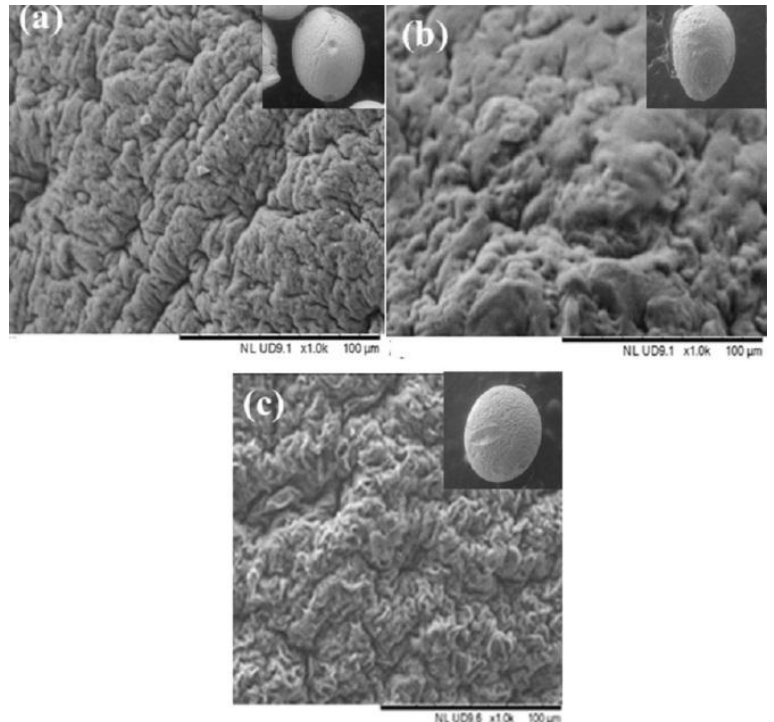

Fig 1: SEM micrograph of beads Alg at (a), Alg-MWCNT (b) and Alg$\mathrm{GO}(\mathrm{c})$

\subsection{Adsorption studies}

\subsubsection{Effect of medium acidity}

Medium acidity is expected to significantly influence the efficiency of dyes removal. In this work, different $\mathrm{pH}$ values in the range of 3-12 were investigated by adjusting the sample solution with $1.0 \mathrm{M} \mathrm{HCl}$ and $0.1 \mathrm{NaOH}$ solution. Fig. 2 shows the adsorption of $\mathrm{MB}$ dye significantly increases from $\mathrm{pH} 3$ to 10 . The differences in adsorption behavior under various $\mathrm{pH}$ values can be explained due to electrostatic forces between the surface of beads and MB dyes. At $\mathrm{pH}$ below than 5 , the carboxylate groups of alginate tend protonated, leading to less electrostatic forces between the MB and adsorbents molecular structure. Also, under acidic conditions, massive quantities of $\mathrm{H}_{3} \mathrm{O}+$ ions existed, which can compete with dye cations adsorbing on the active sites, resulting in the lower removal percentage [36-38]. While, at mild acid to basic medium, the alginate presence at natural structure. Thus, the interaction between at their optimum condition due to contribution of electrostatic, hydrophobic and $\pi-\pi$ interaction form both alginate and aromatic rings of carbonaceous materials [22]. Therefore, $\mathrm{pH} 10$ of aqueous solutions was suggested for subsequent experiment to get high percentage removal of MB.

\subsubsection{Effect of contact time}

Contact time is an important parameter to determine the equilibrium time and kinetics of adsorption process. Thus, in this study, the effect of contact time on adsorption MB was determined by exposing the prepared beads in aqueous sample for different lengths of time in the range of 30-300 min. The results as shown in Fig. 3 revealed that the adsorption activities significantly increased with contact time of up to $180 \mathrm{~min}$, beyond which it gradually decreased [39]. It is clearly show that the adsorption process of MB on Alg-MWCNT and Alg-GO adsorbents has adsorption capacity higher than Alg adsorbents. This could be attributed to the considerable hydrophobic and hydrophobic and $\pi-\pi$ interaction of abundance of aromatic rings in the nanocarbonaceous materials $[18,40]$. It was observed that adsorption of MB onto Al-GO 20\% higher than adsorption of Al-MWCNT. This phenomena could be explained by presence of graphite planar sheet and massive quantities oxygen-containing functional groups of GO at exterior surface of the beads provide easy pathway for the adsorption to occurred [41]. However, nature of multi layered wall of porous MWCNTs might be difficult for the MB structure to pass through, thus inhibit the adsorption to occurred between layer.

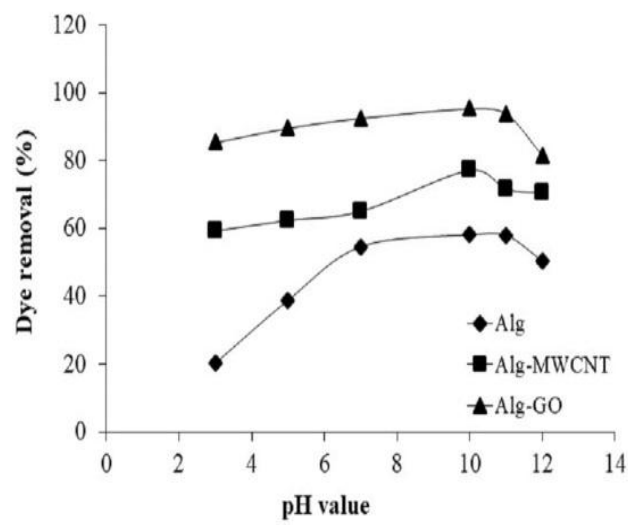

Fig. 2: Effect of medium acidity on the removal of MB by prepared adsorbents at $27{ }^{\circ} \mathrm{C}$, stirring speed $400 \mathrm{rpm}, 0.10 \mathrm{~g}$ adsorbents, initial concentration $20 \mathrm{mg} / \mathrm{L}$ and contact time $30 \mathrm{~min}$.

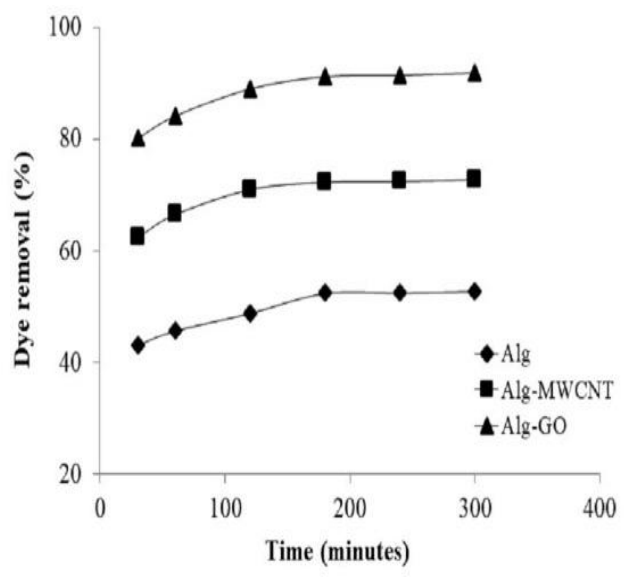

Fig. 3: Effect of contact time on the removal of MB by prepared adsorbents at $27^{\circ} \mathrm{C}$, stirring speed $400 \mathrm{rpm}, 0.10 \mathrm{~g}$ adsorbents, initial concentration $20 \mathrm{mg} / \mathrm{L}$ and optimum $\mathrm{pH} 10$.

\subsubsection{Adsorption kinetics}

The kinetic study of MB adsorption onto Alg and Alg-GO adsorbents were determined using three common models being pseudofirst-order model (Eq. 1), pseudo-second-order model (Eq. 2), and intraparticle diffusion model (Eq. 3), respectively.

$\log \left(q_{e}-q_{t}\right)=\log q_{e}-\left(k_{1} \mathrm{t} / 2.303\right)$

$\left(\mathrm{t} / q_{t}\right)=\left(1 / k_{2} q_{e}^{2}\right)+\left(\mathrm{t} / q_{e}\right)$

$q_{t}=k_{3} t^{1 / 2}+C$

where qt $(\mathrm{mg} / \mathrm{g})$ and qe $(\mathrm{mg} / \mathrm{g})$ represent the adsorption capacities at time $\mathrm{t}$ and at equilibrium respectively; $\mathrm{k}_{1}(\mathrm{~g} /(\mathrm{mg} \cdot \mathrm{min})), \mathrm{k}_{2}$ (g/(mg.min) ) and $\mathrm{k}_{3}\left(\mathrm{~g} /\left(\mathrm{mg} \cdot \mathrm{min}^{1 / 2}\right)\right.$ are the first-order, secondorder, and intraparticle diffusion rate constants, respectively; $\mathrm{C}$ is the intercept of intraparticle diffusion model. The fitting results are summarized in Fig. 4 and Table 2. The suitability was determined by introducing the correlation coefficient $\left(\mathrm{R}^{2}\right)$. The closer the value $\mathrm{R}^{2}$ to 1 , the more applicable the model was. For all MB concentration $(20,40,60,80$ and $100 \mathrm{mg} / \mathrm{L})$, the correlation for pseudo-second-order model (0.9995) was much larger than that for the pseudo-first-order model (0.9143), indicating that MB adsorption onto Alg beads, Alg-MWCNT and Alg-GO beads can be described as pseudo-second-order model. The adsorption capacities calculated by pseudo-second-order model were close to those determined by the experiments. As conclusion, MB adsorption on Alg, Alg-MWCNT and Alg-GO beads can be described as pseudo-second-order model which described the chemical adsorption behavior. 


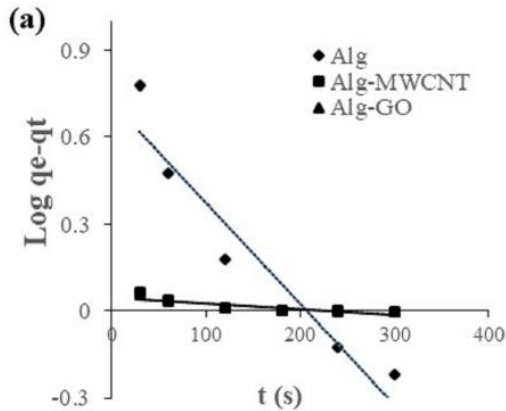

(b)

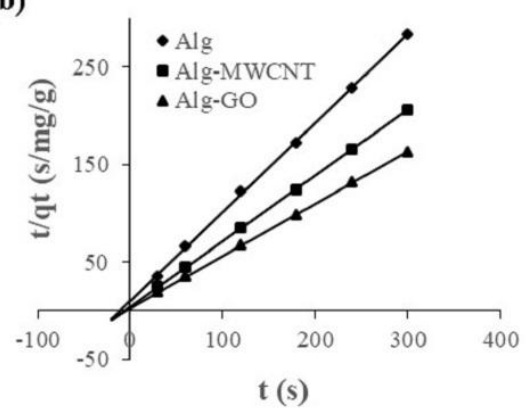

(c)

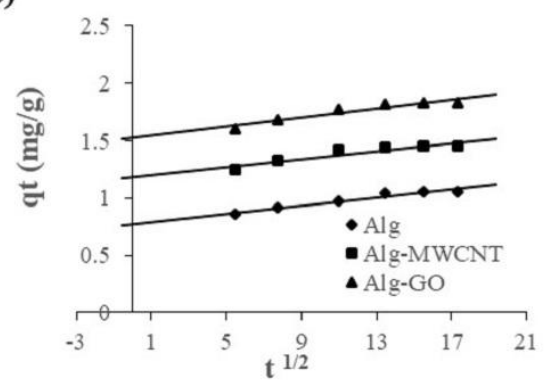

Fig. 4: Adsorption kinetics of MB on Alg, Alg-MWCNT and Alg-GO beads fitted to the pseudo-first order rate model (a), pseudo-second order rate model (b) and intraparticle diffusion (c)

Table 2: Calculated values of parameters for pseudo-first-order, pseudosecond-order and the intraparticle diffusion model of the Alg, AlgMWCNT and Alg-GO beads

\begin{tabular}{|c|c|c|c|c|}
\hline \multirow[b]{2}{*}{ Model } & \multirow[b]{2}{*}{ Parameter } & \multicolumn{3}{|c|}{ Adsorbents } \\
\hline & & Alg & $\begin{array}{c}\text { Alg- } \\
\text { MWCNT }\end{array}$ & Alg-GO \\
\hline \multirow{2}{*}{$\begin{array}{l}\text { pseudo- } \\
\text { first-order }\end{array}$} & $\begin{array}{c}\mathrm{q}_{\mathrm{e}} \\
\left(\mathrm{mg} \mathrm{g}^{-1}\right)\end{array}$ & 5.29 & 1.31 & 1.12 \\
\hline & $\mathrm{k}_{1}\left(\mathrm{~min}^{-1}\right)$ & $\begin{array}{c}8.06 \times 10^{-3} \\
0.914\end{array}$ & $\begin{array}{c}5.43 \times 10^{-4} \\
0.743\end{array}$ & $\begin{array}{c}4.61 \times 10^{-4} \\
0.794\end{array}$ \\
\hline \multirow{2}{*}{$\begin{array}{l}\text { pseudo- } \\
\text { second- } \\
\text { order }\end{array}$} & $\underset{\mathrm{qe}_{\mathrm{e}}}{\left.\mathrm{qg}^{-1}\right)}$ & 1.10 & 0.98 & 1.88 \\
\hline & $\mathrm{k}_{1}\left(\min ^{-1}\right)$ & $\begin{array}{c}8.552 \times 10^{-2} \\
0.999\end{array}$ & $\begin{array}{c}9.35 \times 10^{-2} \\
1\end{array}$ & $\begin{array}{c}9.193 \times 10^{-2} \\
1\end{array}$ \\
\hline \multirow{2}{*}{$\begin{array}{l}\text { intraparticle } \\
\text { diffusion }\end{array}$} & $\begin{array}{c}\mathrm{C} \\
\left(\mathrm{mg} \mathrm{g}^{-1}\right)\end{array}$ & 0.78 & 1.39 & 1.53 \\
\hline & $\mathrm{K}_{3}\left(\mathrm{~min}^{-1}\right)$ & $\begin{array}{c}1.75 \times 10^{-2} \\
0.940\end{array}$ & $\begin{array}{c}1.99 \times 10^{-2} \\
0.864\end{array}$ & $\begin{array}{c}1.980 \times 10^{-2} \\
0.903\end{array}$ \\
\hline
\end{tabular}

\subsubsection{Effect of initial concentration}

The influence of initial dye concentration in equilibrium uptake of MB dye by Alg, Alg-MWCNT and Alg-GO adsorbents were presented Fig. 5. The initial dye concentrations were varied from 20 $100 \mathrm{mg} / \mathrm{L}$ while keeping the other parameters as constant. From observation, the percentage removal of dye decreases with more than $20 \mathrm{mg} / \mathrm{L}$ MB concentration. This might be due to limitation of adsorbents capacity, where it become saturated at particular concentration [27]. As such at higher concentrations, more MB dye molecules are left unabsorbed in the solution resulting in decreased of dye removal percentage.

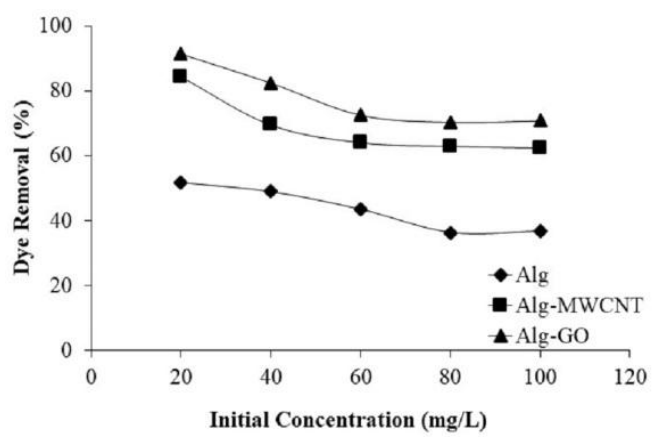

Fig 5: Effect of initial concentration on the removal of MB by prepared adsorbents at $27{ }^{\circ} \mathrm{C}$, stirring speed $400 \mathrm{rpm}, 0.10 \mathrm{~g}$ adsorbents, at optimum $\mathrm{pH} 10$ and 180 min contact time.

\subsubsection{Adsorption Isotherm}

In order to determine quantitatively the adsorption of $\mathrm{MB}$ onto Alg, Alg-MWCNT and Alg-GO, Langmuir and Freundlich models were utilized to describe the sorption isotherms of MB on prepared adsorbents. The Langmuir isotherm model presented that a monolayer adsorption specify that the adsorbent has a finite capacity for adsorbate to be adsorbed onto the adsorbent, all the sites are energetically equilibrium, and there is no interaction between the adsorbed molecules [42]. The Freundlich model is a multilayer adsorption on heterogeneous surfaces with interaction between adsorbed molecules where the energy is reduced upon completion of the sorption sites of the adsorbent [43].The linear form of Langmuir and Freundlich equations were expressed in (Eq. 4) and (Eq.5) respectively.

$\left(C_{e} / q_{e}\right)=\left(1 / q_{\max } K_{L}\right)+\left(C_{e} / q_{\max }\right)$

$\log q_{e}=\log K_{F}+(1 / n) \log C_{e}$

where $\mathrm{q}_{\max }$ is defined as the capacity of adsorbent $(\mathrm{mol} / \mathrm{g}), \mathrm{q}_{\mathrm{e}}$ is the equilibrium adsorptive quantity of the adsorbate per gram of adsorbent $(\mathrm{mol} / \mathrm{g}), \mathrm{C}_{\mathrm{e}}$ is the equilibrium adsorbate concentration $(\mathrm{mg} / \mathrm{L}) . \mathrm{K}_{\mathrm{L}}$ and $\mathrm{K}_{\mathrm{F}}$ is the Langmuir and Freundlich adsorption constant respectively and $\mathrm{n}$ is the Freundlich exponential coefficient.

Adsorption isotherms of $\mathrm{MB}$ on $\mathrm{Alg}$, Alg-MWCNT and Alg-GO are summarized in Table 3. All three adsorbents gave correlation coefficient for Freundlich equation $\left(\mathrm{R}^{2}>0.9716,0.9604\right.$ and 0.9752 , which were better than Langmuir equation $\left(\mathrm{R}^{2}>0.9434\right.$, 0.8223 and 0.8867 ) respectively. It is indicating that, the adsorption of MB onto these adsorbents may occurs in a multilayer adsorption on varied surfaces with possible interactions taking place between the adsorbed molecules and that the adsorption energy depletes upon equilibrium. Thus, isotherm adsorption equation of MB onto these adsorbent fitted better to the Freundlich isotherm model.

Table 3: Calculated values of parameters in Langmuir and Freundlich equations.

\begin{tabular}{|c|c|c|c|c|}
\hline \multirow[b]{2}{*}{ Model } & \multirow[b]{2}{*}{ Parameter } & \multicolumn{3}{|c|}{ Adsorbents } \\
\hline & & Alg & $\begin{array}{c}\text { Alg- } \\
\text { MWCNT }\end{array}$ & Alg-GO \\
\hline \multirow{3}{*}{ Langmuir } & $\mathrm{q}_{\max }(\mathrm{mol} / \mathrm{g})$ & 5.886 & 8.599 & 8.361 \\
\hline & $\mathrm{K}_{\mathrm{L}}(\mathrm{L} / \mathrm{mol})$ & 1.265 & 0.272 & 0.140 \\
\hline & $\mathrm{R}^{2}$ & 0.943 & 0.822 & 0.887 \\
\hline \multirow{3}{*}{ Freundlich } & $\mathrm{K}_{\mathrm{F}}(\mathrm{mol} / \mathrm{g})$ & 0.268 & 0.885 & 1.392 \\
\hline & $\mathrm{n}$ & 1.592 & 1.976 & 2.236 \\
\hline & $\mathrm{R}^{2}$ & 0.972 & 0.960 & 0.975 \\
\hline
\end{tabular}

All data on the effect of medium acidity, contact time and initial concentration for adsorption capacity (qt) and percentage dye removal $(\% \mathrm{R})$ for prepared adsorbents were Tabulated in Table 4. 
Table 4: Summarized data on the effect of medium acidity $(\mathrm{pH})$ on removal of MB by Alg, Alg-MWCNT and Alg-GO beads.

\begin{tabular}{cccc}
\hline Parameter & \multicolumn{3}{c}{$\begin{array}{c}\text { Adsorption capacity, qt (mg/g), } \\
\text { (Dye removal, \%) }\end{array}$} \\
\hline Acidity (pH) & Alg & Alg-MWCNT & Alg-GO \\
\hline 3 & $0.40(20)$ & $1.18(59)$ & $1.71(85)$ \\
5 & $0.67(33)$ & $1.25(62)$ & $1.80(90)$ \\
7 & $1.09(54)$ & $1.03(65)$ & $1.85(92)$ \\
10 & $1.16(58)$ & $1.54(77)$ & $1.91(95)$ \\
11 & $1.16(58)$ & $1.43(72)$ & $1.88(94)$ \\
12 & $1.00(50)$ & $1.41(71)$ & $1.63(81)$ \\
\hline Time (min) & Alg & Alg-MWCNT & Alg-GO \\
\hline 30 & $0.86(43)$ & $1.25(62)$ & $1.60(80)$ \\
60 & $0.91(46)$ & $1.33(66)$ & $1.68(84)$ \\
120 & $0.98(49)$ & $1.42(71)$ & $1.78(89)$ \\
180 & $1.05(52)$ & $1.45(72)$ & $1.82(91)$ \\
240 & $1.05(52)$ & $1.45(72)$ & $1.83(91)$ \\
300 & $1.05(52)$ & $1.45(72)$ & $1.83(91)$ \\
\hline Initial conc. & Alg & Alg-MWCNT & Alg-GO \\
$($ ppm) & & $1.69(84)$ & $1.83(91)$ \\
\hline 20 & $1.04(52)$ & $2.78(70)$ & $3.30(82)$ \\
40 & $1.97(49)$ & $3.84(64)$ & $4.35(73)$ \\
60 & $2.61(44)$ & $5.03(63)$ & $5.63(71)$ \\
80 & $2.90(36)$ & $6.23(62)$ & $7.0870)$ \\
100 & $3.66(35)$ & &
\end{tabular}

\section{Conclusion}

Three adsorbents Alg, Alg-MWCNT and Alg-GO were successfully prepared and was confirm by FTIR and SEM analysis. The effects of experimental parameters on the MB removal were investigated by conditions optimization of adsorbents contact time, sample $\mathrm{pH}$, and initial concentration of $\mathrm{MB}$. The optimum conditions obtained as follow; 180 minutes contact time, $20 \mathrm{mg} / \mathrm{L}$ of initial concentration at sample $\mathrm{pH} 10$.

The encapsulated carbonaceous alginate beads provide higher percentage MB removal as compared to alginate beads due to additional hydrophobic and $\pi-\pi$ interaction contributed from aromatic rings of MWCNTs and GO. The freundlich and langmuir models were used to describe the isotherms and the freundlich model was shown to provide the best fitting. From kinetic studies, it showed that the adsorption process was more accurately represented by a pseudo second-order model.

\section{Acknowledgement}

The authors wish to thank Universiti Teknologi MARA for facilitations and the Ministry of Education Malaysia for their financial supports through vote number 600-IRMI/FRGS 5/3 (039/2017) (FRGS/1/2017/STG01/UITM/02/8) and 600-IRMI/MyRA 5/3/LESTARI (098/2017)

\section{References}

[1] Jung W, Jeon B-H, Cho D-W, Roh H-S, Cho Y, Kim S-J \& Lee DS (2015), Sorptive removal of heavy metals with nano-sized carbon immobilized alginate beads. Journal of Industrial and Engineering Chemistry 26, 364-369.

[2] Noroozi B \& Sorial GA (2013), Applicable models for multicomponent adsorption of dyes: a review. Journal of Environmental Science 25, 419-429.

[3] Meziti C \& Boukerroui A (20140, Reuse of solid waste in adsorption of the textile dye. Physics Procedia 55, 173-178.

[4] Konicki W, Cendrowski K, Bazarko G \& Mijowska E (2015), Study on efficient removal of anionic, cationic and nonionic dyes from aqueous solutions by means of mesoporous carbon nanospheres with empty cavity. Chemical Engineering Research and Design 94, 242-253.

[5] Yadav AK, Dash P, Mohanty A, Abbasi R \& Mishra BK (2012), Performance assessment of innovative constructed wetlandmicrobial fuel cell for electricity production and dye removal. Ecological Engineering 47, 126-131.
[6] Gupta VK, Mohan D, Sharma S \& Sharma M (2000), Removal of basic dye (Rhodamine B and Methylene blue) from aqueous solutions using bagasse fly ash. Separation Science and Technology 35 , 2097-2113.

[7] Cataldo S, Gianguzza A, Pettignano A \& Villaescusa I (2012), Mercury(II) removal from aqueous solution by sorption onto alginate, pectate and polygalacturonate calcium gel beads. A kinetic and speciation based equilibrium study. Reactive and Functional Polymers 73, 207-217.

[8] Meshko V, Markovska L, Mincheva M \& Rodrigues AE (2011), Adsorption of basic dyes on granular activated carbon and natural zeolite. Water Resources 35, 3357-3366.

[9] El Haddad M, Slimani R, Mamouni R, El Antri S \& Lazar S (2013), Removal of two textile dyes from aqueous solutions onto calcined bones. Journal of Association Arab Universities for Basic and Applied Sciences 14, 51-59.

[10] Huang CH, Chang KP, Ou HD, Chiang YC \& Wang CF. (2011), Adsorption of cationic dyes onto mesoporous silica. Microporous Mesoporous Materials 141, 102-109.

[11] Afkhami A, Saber TM \& Bagheri H (2010), Modified maghemite nanoparticles as an efficient adsorbent for removing some cationic dyes from aqueous solution. Desalination 263, 240-248.

[12] Yash M, Jitendra M, Abhijeet S, Amla B \& Madan MS (2015), In vivo and in vitro histological localization of endophytic fungi in Tinospora cordifolia (Willd.) Miers ex Hook F. \& Thomas. Journal of Applied Research on Medicinal and Aromatic Plants 2, 30-33.

[13] Lunhong A \& Jing J (2012), Removal of methylene blue from aqueous solution with self-assembled cylindrical graphene-carbon nanotube hybrid. Journal of Industrial and Engineering Chemistry 192, 156-163.

[14] Latorre CH, Mendez JA, García JB, Martín SG \& Pena Crecente RM (2012), Carbon nanotubes as solid-phase extraction sorbents prior to atomic spectrometric determination of metal species: A review. Analytica Chimica Acta 749, 16-35.

[15] Dahane S, Gil Garcia MD, Martinez Buenoa MJ, Ucles Morenoa A, Martinez Galera M \& Derdour A (2013), Determination of drugs in river and wastewaters using solid-phase extraction by packed multiwalled carbon nanotubes and liquid chromatography-quadrupolelinear ion trap-mass spectrometry. Journal of Chromatography A 1297, 17-28.

[16] Li S, He M, Li D \& Pan Z (2017), Removal of humic acid from aqueous solution by magnetic multi-walled carbon nanotubes decorated with calcium. Journal of Molecular Liquids 230, 520-528.

[17] Li YH, Zhang P, Du Q, Peng X, Liu T \& Wang Z (2011), Adsorption of fluoride from aqueous solution by grapheme. Journal of Colloid and International Science 363, 348-354.

[18] Liu T, Li YH, Du Q, Sun J, Jiao Y \& Yang G (2012), Adsorption of methylene blue from aqueous solution by graphene. Colloids and Surfaces B 90, 197-203.

[19] Devi GK, Kumar PS \& Kumar KS (2016), Green synthesis of novel silver nanocomposite hydrogel based on sodium alginate as an efficient biosorbent for the dye wastewater treatment: prediction of isotherm and kinetic parameter. Desalination and Water Treatment 57(57), 27686-27699.

[20] Wan Ibrahim WN, Sanagi MM, Hanapi MNS \& Wan Ibrahim WA (2015), Preparation of Chemically Stable Multi-Wall Carbon Nanotubes Reinforced Blended Agarose/Chitosan Composite Film. Der Pharma Chemica 6, 353-356.

[21] Platero E, Fernandez ME, Bonelli PR \& Cukierman AL (2017), Graphene oxide/alginate beads as adsorbents: Influence of the load and the drying method on their physicochemical-mechanical properties and adsorptive performance. Journal of Colloid and International Science 491, 1-12.

[22] Wan Ibrahim WN, Sanagi MM, Hanapi MNS, Kamaruzaman S, Yahaya N \& Wan Ibrahim WA (2018), Solid-phase microextraction based on an agarose-chitosan-multiwalled carbon nanotube composite film combined with HPLC-UV for the determination of nonsteroidal anti-inflammatory drugs in aqueous samples. Journal of Separation Science 41, 2942-2951.

[23] Cardoso NF, Lima EC, Pinto IS, Amavisca CV, Royer B \& Pinto RB (2011), Application of cupuassu shell as biosorbent for the removal of textile dyes from aqueous solution. Journal of Environmental Management 92, 1237-1247.

[24] Kaygusuz H \& Erim B (2014), Removal of Fluoride from Aqueous Solution Using Aluminum Alginate Beads, Water 43, 724-730.

[25] Khodaie M, Ghasemi N, Moradi B \& Rahimi M (2013), Removal of methylene blue from wastewater by adsorption onto $\mathrm{ZnCl}_{2}$ acti- 
vated corn husk carbon equilibrium studies. Journal of Chemistry 2013, 1-6.

[26] Sanagi, MM, Loh SH, Wan Ibrahim WN, Neda P, Salisu A, Wan Ibrahim WA \& Ali I (2016), Review Article - Agarose and alginate-based biopolymers for sample preparation: Excellent green extraction tools for this century. Journal of Separation Science 39 1152-1159.

[27] Rocher V, Siaugue JM, Cabuil V \& Bee A (2008), Removal of organic dyes by magnetic alginate beads. Water Research 42, 12901298.

[28] Qu X, Alvarez PJJ \& Li Q (2013), Applications of nanotechnology in water and wastewater treatment, Water Research 47, 3931-3946.

[29] Jiao C, Xiong J, Tao J, Xu S, Zhang D, Lin H \& Chen Y (2016), Sodium alginate/graphene oxide aerogel with enhanced strengthtoughness and its heavy metal adsorption study. International Journal of Biological Macromolecules 83, 133-141.

[30] Tang R, Chong D, Li C, Liu W, Gao S \& Wang C (2017), Removal of Methylene Blue from Aqueous Solution Using Agricultural Residue Walnut Shell: Equilibrium, Kinetic, and Thermodynamic Studies. Journal of Chemistry 2017, 1-10.

[31] Fei Y, Yong L, Sheng H \& Jie M (2016), Adsorptive removal of ciprofloxacin by sodium alginate/graphene oxide composite beads from aqueous solution. Journal of Colloid and Interface Science 484, 196-204.

[32] Balavandy SK, Shameli K \& Abidin, ZZ (2015), Rapid and green synthesis of silver nanoparticles via sodium alginate media. International Journal of Electrochemical Science 10, 486-497.

[33] Vu HC, Dwivedi AD, Le TT, Seo S-H, Kim E-J \& Chang Y-S (2016), Magnetite graphene oxide encapsulated in alginate beads for enhanced adsorption of $\mathrm{Cr}(\mathrm{VI})$ and $\mathrm{As}(\mathrm{V})$ from aqueous solutions: role of crosslinking metal cations in $\mathrm{pH}$ control. Chemical Engineering Journal 307, 220-229.

[34] Wang B, Gaob B, Zimmermand R \& Lee X (2018), Impregnation of multiwall carbon nanotubes inalginate beads dramatically enhances their adsorptive ability to aqueous methylene blue. Chemical Engineering Research and Design 133, 235-242.

[35] Fei Y, Yong L, Sheng H \& Jie M (2016), Adsorptive removal of ciprofloxin by sodium alginate/graphene oxide composite beads from aqueous solution. Journal of Colloid and Interface Science 484, 196-204.

[36] Tang R, Dai C, Li C, Liu W, Gao S \& Wang C (2017), Removal of Methylene Blue from Aqueous Solution Using Agricultural Residue Walnut Shell: Equilibrium, Kinetic, and Thermodynamic Studies. Journal of Chemistry 2017, 1-10.

[37] Guo JZ, Li B, Liu L \& Liv K (2014), Removal of methylene blue from aqueous solutions by chemically modified bamboo. Chemosphere $111,225-231$.

[38] Rahmayanti M, Santosa SJ \& Sutarno (2016), Comparative Study on the Adsorption of [AuCl4]-onto Salicylic Acid and Gallic Acid Modified Magnetite Particles. Indonesian Journal of Chemistry 16, 329-337.

[39] Aravindhan R, Fathima NN, Rao JR \& Nair BU (2007), Equilibrium and thermodynamic studies on the removal of basic black dye using calcium alginate beads. Colloids and Surfaces A 299, 232 238.

[40] Li Y, Qiuju Du Q, Liu T, Sun J, Wang Y, Wu S, Wang J, Xia Y \& Xi L (2013), Methylene blue adsorption on graphene oxide/calcium alginate composites. Carbohydrate Polymers 95, 501- 507.

[41] Bhattacharya AK, Mandal SN \& Das SK (2006), Adsorption of Zn (II) from aqueous solution by using different adsorbents. Chemical Engineering Journal 123, 43-51.

[42] Etim UJ, Umoren SA \& Eduok UM (2016), Coconut coir dust as a low cost adsorbent for the removal of cationic dye from aqueous solution. Journal of Saudi Chemical Society 20, 67-76.

[43] Crini G \& Badot PM (2008), Application of chitosan, a natural amino polysaccharide, for dye removal from aqueous solutions by adsorption processes using batch studies: A review of recent literature. Progress in Polymer Science 33, 399-447. 